\section{Approach behavior to visual stimuli in chicks and rats}

\author{
J. DUTCH and L. B. BROWN \\ Victoria University of Wellington, Wellington, New Zealand
}

A comparison was made of the approach behavior of chicks and rats to visual stimuli that differed in complexity. Both chicks and rats showed a preference for the least complex stimulus. Running times, however, differed over trials, with chicks increasing in speed and rats decreasing in speed.

Several studies have demonstrated the effectiveness of novelty in evoking an approach response in rats (Thompson \& Solomon, 1954; Berlyne, 1955). Others have shown that rats show a preference for the more complex of two stimuli (Dember et al. 1957; Baker \& Franken, 1967).

Using a paired-comparison method, Dutch (1969) found that under certain conditions chicks approached the more complex of two stimuli: however. when the choice was between a previously seen stimulus and a new, less complex stimulus, the tendency for the Ss to choose the more complex stimulus declined. This suggests that if novelty were maximized. it might be a more effective determinant of approach behavior than is complexity. The following experiment was designed to test this hypothesis.

\section{SUBJECTS}

Fifteen 30-day-old male Sprague-Dawley rats from the Victoria University colony and 15 6-day-old Australorp chicks from the Wallaceville Animal Research Station, all experimentally naive. were the Ss. The rats were housed in group cages with a sawdust floor, and the chicks were housed in a single-cage brooder with a brown paper floor. For all $S s$ food and water were ad lib. and no pretraining was given.

\section{APPARATUS}

The experimental apparatus consisted of a hollow $Y$ made up of a startbox, measuring $30 \times 15 \times 23 \mathrm{~cm}$ high, and two goalboxes, measuring $38 \times 25 \times 23 \mathrm{~cm}$ high. All boxes were equipped with perspex covers and aluminum guillotine doors. The sides of the whole apparatus were made of aluminum. For rats a sawdust floor was used and for chicks the

Table 1

Percent Choosing the Less-Complex Stimulus. With Corresponding $\mathrm{P}$ Values from the Binomial Test

\begin{tabular}{lcccc}
\hline Trial & $\begin{array}{c}\text { Chicks } \\
?\end{array}$ & $\mathbf{P}$ & $\begin{array}{c}\text { Rats } \\
\widetilde{c}\end{array}$ & $\mathrm{P}$ \\
\hline 1 & 60 & .304 & 66.6 & .151 \\
2 & 73.3 & .059 & 80.0 & .018 \\
3 & 66.6 & .151 & 60.0 & .304 \\
4 & 66.6 & .151 & 73.3 & .059 \\
5 & 73.3 & .059 & 86.6 & .004 \\
\hline
\end{tabular}

floor was covered with brown paper, corresponding to their respective living cages. The two goalboxes were set at an angle to each other so that the focal point from the center of the stimulus cards bisected a point $7.5 \mathrm{~cm}$ from the startbox door. The distance from the door of the startbox to each stimulus card was $1 \mathrm{~m}$. The area bounded by the boxes and side walls thus formed a pentagon. PROCEDURE

The apparatus was placed in a darkened room, the only light being from two $2-W$ bulbs in each goalbox. These lights were wired behind the 3-cm-wide aluminum strips placed at each side of each goalbox. which acted as guides for the guillotine doors. No direct light from the bulbs was visible inside the pentagon. The level of illumination on each card was $7 \mathrm{fL}$, and the level of illumination in the startbox was $0.113 \mathrm{fL}$.

The stimulus panels were white cardboard rectangles $23 \mathrm{~cm}$ long and $12.5 \mathrm{~cm}$ high. They were held in place in the goalboxes by wooden frames. The stimuli were made by painting outlined geometric figures in black on a white ground. "Stimulus complexity" was defined by the number of black and white parts on each card. The stimuli were "novel," since no S had had any prior exposure to the stimulus patterns used in the experiment. The stimuli were presented in pairs, one card having a single form of the stimulus figure and the other card having several concentric forms, spaced at $0.5 \mathrm{~cm}$, of the same stimulus figure. The order of presentation was from the least complex to the most complex. so that for all Ss the stimuli on Trial 1 consisted of one diamond against two diamonds. and on Trial 5 the stimuli were one circle against six circles. The positions of the stimuli were randomized for each $\mathrm{S}$ for each trial. The stimulus cards were constructed so that the total area of black was the same for each pair of cards. and the figures used (with the number on the paired card) were a diamond (2), hexagon (3). square (4). vertical lines (5), and circle (6)

Ss were taken individually to the
Table 2

Mean Running Time in Seconds to the Less- and More-Complex Stimuli

\begin{tabular}{ccrrrr} 
& \multicolumn{2}{c}{ Chicks } & & \multicolumn{2}{c}{ Rats } \\
\cline { 2 - 3 } & \multicolumn{2}{c}{ Complexity } & & \multicolumn{2}{c}{ Complexity } \\
\cline { 2 - 3 } \cline { 5 - 6 } Trial & \multicolumn{1}{c}{ Less } & More & & \multicolumn{1}{c}{ Less } & More \\
\hline 1 & 325.0 & 287.0 & & 65.7 & 46.6 \\
2 & 144.0 & 52.3 & & 149.0 & 58.3 \\
3 & 40.1 & 30.7 & & 309.1 & 285.6 \\
4 & 53.3 & 25.7 & & 310.8 & 184.2 \\
5 & 16.0 & 27.3 & 560.3 & 373.5 \\
\hline
\end{tabular}

experimental room, placed in the startbox and $1 \mathrm{~min}$ later the startbox door was raised. Movement was allowed freely for an unlimited time, and when the $S$ entered either of the goalboxes, that goalbox door was lowered and he was kept in the box for $5 \mathrm{sec}$ before being returned to the startbox to await the next trial. The intertrial interval was $1 \mathrm{~min}$, during which the stimulus cards were changed; each $S$ was given five massed trials. The times recorded by stopwatch were from the opening of the startbox until $\mathrm{S}$ had completely entered the goalbox. The choice of stimulus was also recorded.

\section{RESULTS}

The results showed that overall the less complex stimulus was chosen by chicks on $68 \%$ of the trials and by rats on $73.3 \%$ of the trials.

From Table $l$ it is apparent that under these conditions both chicks and rats approach the less complex stimulus more frequently.

From Table 2 it is apparent that changes in the times taken by chicks and rats to choose the less complex stimulus move in contrary directions. The running time for chicks decreases over trials and for rats it increases over trials.

\section{CONCLUSIONS}

The results suggest that, although the less complex stimulus is apparently preferred, the approach response to the stimuli is being extinguished for rats but not for chicks. Presumably this reflects the differential importance of the visual system in these two species. Further research is needed to clarify the reasons for the times being slower for the less complex stimulus in both groups (except for the chicks' four-stimulus comparison). But notice that spaced trials produce a different pattern of choices with rats, suggesting that there may be an optinum level of complexity (Dutch and Brown, in preparation)

\section{REFERENCES}

BAKER, J. G., \& FRANKEN, R. E. Alternation as a function of drive level and visual complexity. Psychonomic Science. 1967.8, 91-92.

BERLYNE. D. E. The arousal and satiation of 
perceptual curiosity in the rat, Journal of Comparative \& Physiological Psychology, $1955,48,238-246$.

DEMBER, W. N., EARL, R. W.. \& PARADISE N. Response by rats to differential stimulus complexity. Journal of Comparative \& Physiological Psychology, 1957, 50, 514-518.
DUTCH, J. Visual complexity and stimulus pacing in chicks. Quarterly Journal of Experimental Psychology, 1969, 21, 63-66.

THOMPSON, W. R., \& SOLOMON, L. M. Spontaneous pattern discrimination in the rat. Journal of Comparative \& Physiological Psychology, 1954, 47, 104-107.

\section{Discrimination of orientation by rats}

\section{MARCEL KINSBOURNE \\ Division of Pediatric Neurology, Duke Medical Center, Durham, N.C. 27706}

Learning to discriminate along the dimension of orientation, rats experienced decreasing difficulty depending on whether the figures were reversed, inverted, reversed and inverted, or rotated, relative to each other, a hierarchy identical to that previously established in humans.

Though rats can easily learn to discriminate horizontal lines from vertical, they cannot discriminate opposing obliques (Lashley, 1938) except in a situation specially designed to attract their attention to the orientational aspects of the total display (Kinsbourne, 1967). However, rats' ability to learn to discriminate the orientation of two-dimensional figures appears not to have been studied. Children have a notorious tendency to treat different orientations of a two-dimensional figure interchangeably, particulary when these are in mirror-image relation to each other (Rudel \& Teuber, 1963; Huttenlocher, 1967). Kinsbourne \& Hartley (1968) showed that children's relative difficulty in coping with orientation of a "p"-like ("lamb chop" of Wechsler \& Hagin, 1964) shape was consistently maximal for mirror-image reversed pairs, less for inversions, least for rotations. The hierarchy of confusions made by adults given brief exposures of arrays of the same materials similarly conformed to this sequence. They suggested a hierarchical search model to accommodate their findings. The question arises, is this hierarchy of relative confusibility a characteristic of human information processing or does it represent a more widely applicable strategy? In particular, does the postulated hierarchical search necessarily depend on verbal mediation? To resolve these questions, we confronted rats with the task of discriminating "lamb chop" shapes for reward.

\section{METHOD}

Twenty-eight male hooded rats were divided into four groups of seven each, matched for learning ability on a light-dark discrimination task. The experimental task was to discriminate, for food reward, pairs of "p" shapes. Each group was presented with a different pair of stimuli, as follows:

$$
\begin{array}{lll}
\text { Group } 1 & \stackrel{+}{\rho} q \\
\text { Group } 2 & \stackrel{+}{\rho} b \\
\text { Group } 3 & \stackrel{+}{\rho} d \\
\text { Group } 4 & \stackrel{+}{\rho} & 0
\end{array}
$$

Twenty trials were run on each of a series of consecutive days until attainment of a 9 out of 10 correct criterion or a total of 200 trials.
Table 1

\begin{tabular}{cccl} 
Group & $\mathrm{N}$ & $\begin{array}{c}\text { Number } \\
\text { Achieved } \\
\text { Criterion }\end{array}$ & \multicolumn{1}{c}{$\begin{array}{c}\text { Number of Trials } \\
\text { to Criterion }\end{array}$} \\
\hline 1 & 7 & 0 & \\
2 & 6 & 1 & 130 \\
3 & 6 & 2 & 110,130 \\
4 & 7 & 5 & $40,80,90,140,200$ \\
\hline
\end{tabular}

\section{RESULTS}

Two animals, one in Group 2 and one in Group 3, had to be withdrawn from the experiment because of sickness. The results with the remaining 26 animals are shown in Table 1. A Kruskal-Wallis one-way analysis of variance reveals significant variance between groups $(H=12, p<0.01)$.

\section{DISCUSSION}

The rats found it easiest to discriminate between the stimuli differing such that one was rotated relative to the other (Group 4). They experienced increasing difficulty with reversal and inversion (Group 3), inversion (Group 2), and reversal (Group 1), in that order. This hierarchy of difficulty corresponds exactly to that established under different circumstances for children and under yet other circumstances for adult humans by Kinsbourne \& Hartley (1968). The generality of this hierarchy excludes verbal mediation as the crucial factor. It is consistent with the view that differences in orientation are not interchangeable, but that there is a hierarchy of salience such that certain orientational disparities are more readily observed, remembered, or in the present instance, used as basis for a working hypothesis to determine the variable relevant to reinforcement. A hierarchical search (Johnson, 1967) is one way of conceptualizing such results.

\section{REFERENCES}

HUTTENLOCHER, J. Children's ability to order and orient objects. Child Development, 1967 , 38, 1169-1176.

JOHNSON, S. C. Hierarchical clustering schemes. Psychometrika, 1967, 32, 241-254.

KINSBOURNE, M. Sameness-difference judgments and the discrimination of obliques in the rat. Psychonomic Science, 1967, 7, 183-189.

KINSBOURNE, M., \& HARTLEY, D. Distinctive feature analysis in children's perception of simple shapes. Paper presented to Social Research \& Child Development, 1968.

LASHLEY, K. S. The mechanism of vision: XV. Preliminary studies of the rat's capacity for detail vision. Joumal of General Psychology, $1938,18,123-193$

RUDEL, R. G., \& TEUBER, H-L. Discrimination of direction of line in children. Joumal of Comparative \& Physiological Psychology, $1963,56,892.898$.

WECHSLER, D., \& HAGIN, R. A. The problem of axial rotation in reading disability. Perceptual \& Motor Skills, 1964, 19.319-326. 